\title{
A solidão como experiência central no totalitarismo no pensamento de Hannah Arendt
}

\author{
Loneliness as the main experience of Totalitarianism \\ in Hannah Arendt's thinking
}

DOI: $10.20873 /$ rpv6n2-05

\section{Antonio Glauton Varela Rocha}

Orcid: 0000-0002-3735-7447

Email: glautonvarela@gmail.com

\begin{abstract}
Resumo
Dentro do pensamento arenditiano, a experiência da solidão é uma das formas mais radicais de afastamento do ser humano da própria humanidade. Para Arendt existem caminhos que podem apontar e conduzir à solidão, e que devem ser vigiados e evitados. Arendt entende que esta experiência tão radical atinge seu ápice no contexto do totalitarismo, em especial nos campos de concentração. A solidão se torna estrutural e é fabricada continuamente no contexto totalitário. Como experiencia onde a pessoa se perde do mundo, dos outros e de si mesma, a solidão é usada pelo regime totalitário como antecipação do aniquilamento final, onde a pessoa se torna um mero feixe vital, um morto vivo, sem expressão do ser pessoa, restando apenas o aniquilamento nos campos.
\end{abstract}

\section{Palavras-chave}

Solidão; Totalitarismo; Campos de Concentração; Comum; Singular.

\begin{abstract}
In Arendtian thinking, the experience of loneliness is one of the most radical ways of moving away the human being from its own humanity. According to Arendt, there are ways that may point out and lead to loneliness, ways that must be watched over and avoided. She understands that such a radical experience reaches its summit in the context of Totalitarianism, especially in regard to concentration camps. Thus, loneliness becomes structural and is continually manufactured inside the totalitarian context. Being one experience where is lost to the world, to others, and to themselves, loneliness as used by the totalitarian regime as an anticipation to final annihilation, where one becomes merely a vital cluster, non-living, without any expression of the being, until nothing is left but decimation in the camps.
\end{abstract}




\section{Keywords}

Loneliness; Totalitarianism; Concentration Camps; Common; Singular.

\section{Um ponto de partida}

De início é salutar explicar que este texto possui alguns pressupostos, e uma vez que em um texto neste formato não tenho como trazer à tona todas as questões que antecedem o tema central do artigo, considero importante deixar estes pressupostos minimamente explicitados.

0 primeiro pressuposto é que o tema abordado neste artigo dialoga diretamente com a tese de que o pensamento de Hannah Arendt é profundamente marcado pelo equilíbrio entre as dimensões do comum e do singular. Entendo que este equilíbrio é uma marca de como a autora entende toda a dimensão da política na vida humana e como ela entende o próprio ser humano. Tendo em vista que não é tema deste artigo o referido equilíbrio, não cabe adentrar os detalhes da argumentação sobre esta questão, no entanto, é pertinente para o tema que trataremos no artigo a consideração sobre que caminhos fomentam o equilíbrio entre o comum e o singular, e quais representam obstáculos ou mesmo riscos ao mesmo. Identifico que o conceito arendtiano que melhor expressa e fomenta a inter-relação entre o comum e o singular é o mundo comum, e o que de modo mais radical leva ao limite da negação do equilíbrio entre o comum e o singular é a solidão.

O segundo pressuposto é compreender o que Arendt se refere ao falar da experiência da solidão. Para entendermos o que Hannah Arendt tinha em mente ao se referir ao termo solidão, é preciso ter ciência que este não era o único conceito com que Arendt se referia à experiência não estarmos na presença de outras pessoas. Arendt expressa esta experiência através de três conceitos: estar-só, isolamento e solidão, respectivamente correspondentes à solitude, isolation e loneliness (esta tradução está presente na versão em português de Origens do Totalitarismo).

Os conceitos acima revelam experiências distintas que temos ao não estarmos na presença de outras pessoas. Esta "não presença” pode se manifestar com significados e impactos diversos na vida das pessoas, sendo este impacto positivo ou negativo. 
Arendt explora relação entre estar só, isolamento e solidão não apenas para explicitar as diferenças entre as três experiências, mas também explicita como o estar só e o isolamento podem apontar para a solidão. Para Arendt as sementes da solidão podem ser encontradas no estar só e no isolamento (cf. GAFFNEY, 2015, p. 7).

O que vai definir uma perspectiva positiva ou negativa do estar só e do isolamento é a relação que a pessoa sozinha ou isolada mantém com mundo (cf. GAFFNEY, 2015, p. 7). Para Arendt “...todo ato de pensar é feito quando se está a sós e constitui um diálogo entre eu e eu mesmo; mas esse diálogo dos dois em um não perde o contato com o mundo dos meus semelhantes... (ARENDT, 2014, p. 636). Há uma separação temporária do mundo, mas os outros estão presentes de certo modo na realidade do dois em um, e enquanto aquele que se recolhe no pensamento se encontra voltado para os outros, ele sempre pode a qualquer momento se juntar a eles (cf. LUCAS, 2019, p. 3). Trata-se daquele tipo de pensamento prático não mais reflete a postura do filósofo que deseja uma verdade fora do contexto relacional. Um tipo de pensamento que “...abandonou a proverbial torre de marfim da mera contemplação” (ARENDT, 2008, p. 95) e do qual para Arendt tinha em Jaspers um exemplo paradigmático. Por outro lado, o estar só também pode cair nesta tentação da torre de marfim da mera contemplação, também pode acabar voltando-se excessivamente e perigosamente apenas para a interioridade. 0 próprio Jaspers teria sido, segundo Arendt, um pensador que desconfiou do estar só. Para ela "Jaspers (...) é o primeiro e único filósofo que sempre protestou contra o estar só [solitude], para quem o estar só aparecia como 'perniciosa'” (ARENDT, 2008, p. 95). Por mais que Arendt entenda que o estar só tenha um papel importante na vida humana, ela defende que esse papel só pode ser preparatório para uma vida propriamente humana (cf. GAFFNEY, 2015, p. 8). 0 dois em um precisa do encontro com os outros para voltar à própria unidade de sua singularidade. Neste sentido, quem vive sozinho sempre corre o risco de cair em solidão sempre não encontrar mais a possibilidade do encontro com os outros "...que os salve da dualidade, do equívoco e da dúvida" (ARENDT, 2014, p. 636).

Também a respeito do isolamento podemos dizer que num primeiro momento o homem isolado permanece em contato com o mundo como obra humana (ARENDT, 2014, p. 633). Mas quando ele se afasta desta referência ao mundo igualmente pode se transformar em solidão. 
Quando homem isolado além de limitado em seu movimento no espaço público é também enfraquecido em suas capacidades produtivas, perde gradualmente a percepção de seu lugar no mundo, rumando para a solidão. Nas palavras de Arendt: "o isolamento pode se tornar solidão, quando sua condição de homo faber é reduzida a animal laborans" (ARENDT, 2014, p. 634).

Em síntese, o que se reforça destas distinções é que o aspecto relacional é fundamental para entendermos a implicação destas três experiências na vida humana. A solidão não teria uma versão positiva, e funcionaria mais como um risco sempre presente de ampliar o deserto na vida humana. Por outro lado, o estar só e o isolamento têm um papel importante na vida humana, mas exatamente por não estarem efetivamente dentro de um contexto relacional, quando se aprofunda o estado de afastamento do mundo e dos outros nestas experiências elas correm o risco de se tornarem caminhos para a solidão.

\section{A solidão como experiência de base do totalitarismo}

No início do texto, sustento o argumento de que a solidão representa a experiência que leva ao limite a separação entre o comum e o singular, neste sentido, é importante evidenciar como esta separação se dá dentro do contexto de maior radicalidade da solidão. Arendt trabalha os caminhos que apontam ou conduzem à solidão a partir da reflexão sobre introspecção romântica e sobre o processo de massificação na sociedade moderna. Mas a manifestação limite da solidão se encontra no totalitarismo, mas especificamente na experiência totalitária dos campos de concentração.

Um fator que pode nos gerar perplexidade a respeito do totalitarismo é que apesar de todas as arbitrariedades praticadas, o regime totalitário se considera plenamente regrado pela lei1. Não se trata das leis humanas, marcadas pela incoerência e indeterminação dos homens, mas as “...leis da natureza ou da história que sempre acreditamos serem a origem de todas as

\footnotetext{
${ }^{1}$ Enquanto o tirano luta contra a lei, o governo totalitário se diz defensor da lei primeira, “...El tirano no se sujeta a ley alguna, su poder es absolutamente arbitrario e 'ilegal'. Por el contrario, el gobierno totalitario desafía toda ley positiva, no para situarse fuera de la ley, sino precisamente para situarse en la fuente de toda ley, para situarse en la Ley. Esto es, el gobierno totalitario pretende seguir la Ley de la Naturaleza o de la Historia, de la que proceden todas las posibles leyes positivas..." (ESQUIROL, 1991, p. 138).
} 
leis" (ARENDT, 2014, p. 605). Os ideais de uma raça pura (lei da natureza) ou da vitória das classes trabalhadoras (lei da história) animaram os projetos dos regimes totalitários examinados por Arendt (respectivamente os regimes alemão e russo). Era preciso eliminar todo e qualquer obstáculo que atrasasse ou dificultasse a efetivação destas leis originárias, e o principal obstáculo considerado pelo totalitarismo foi a espontaneidade humana e a imprevisibilidade daí recorrente $^{2}$. Numa clara inversão do conceito de lei (enquanto nomos), ganharia cada vez mais liberdade de movimento as leis da natureza e da história, quanto mais fosse minada a liberdade de movimento dos homens.

Para realizar este objetivo, o totalitarismo se efetiva num processo que buscava o domínio total. Trata-se de um domínio total porque de fato nenhuma realidade humana escapa deste domínio. Por meio dele o totalitarismo acaba tanto com a vida pública quanto com a interioridade. É um ataque que atinge o ser humano em seus aspectos comum e singular de modo a fechar-se o cerco a qualquer possibilidade da imprevisibilidade humana ${ }^{3}$. Neste intuito o totalitarismo se caracterizará pela construção e disseminação da solidão numa perspectiva estrutural (cf. LUCAS, 2019, p.3). A solidão totalitária se tornou a principal arma para dominação num nível total, onde não escapam nem a dimensão comum nem a dimensão singular das pessoas. A criação da solidão estrutural no totalitarismo se deu especialmente por duas vias. Primeiro através daqueles instrumentos que Arendt considerou como essência e "princípio" do totalitarismo: o terror e a ideologia. E depois, pela solução mais extrema, onde se efetivou o limite da solidão: os campos de concentração. Ao final do processo é desfeito por completo o equilíbrio entre o comum e o singular, uma vez que não há mais nada a equilibrar. A pessoa foi alcançada em sua comunalidade e em sua singularidade. 0 que resta é o homem reduzido a um feixe de sensações, reduzido ao supérfluo, sem qualquer possibilidade de resistência ao movimento da lei da natureza ou da história. Veremos agora em seguida com mais detalhes como os regimes totalitários buscaram efetivar este projeto.

\footnotetext{
2 “...a força sobre-humana da Natureza ou da História tem seu próprio começo e seu próprio fim, de sorte que só pode ser retardada pelo novo começo e pelo fim individual que é, na verdade, a vida de cada homem" (ARENDT, 2014, p. 618).

3 “0 domínio total não permite (...) qualquer atividade que não seja inteiramente previsível” (ARENDT, 2014, p. 612).
} 
O enfrentamento deste projeto começa em Arendt na tentativa de explicar um grande equívoco que seu tempo fazia sobre a relação entre liberdade e política. Arendt enfrentou uma tendência muito forte em sua época que era a de atribuir à política toda uma série de arbitrariedades que o mundo presenciava. Julgava-se então que a política, sendo geradora de tantas arbitrariedades, seria oposta à liberdade (cf. ARENDT, 2013, p. 162). Seguindo este raciocínio, os regimes totalitários poderiam ser interpretados como produtos do excesso de política (cf. JARDIM, 2011, p. 25). 0 que Arendt aponta em suas reflexões é exatamente o contrário (cf. DUARTE, p. 42-43). Para ela o totalitarismo é uma experiência de governo que funciona sem política (Cf. AGUIAR, 1999, p. 100). Neste sentido, nem mesmo podemos falar propriamente do totalitarismo como um sistema político (cf. TASSIN, 1997, p. 384). Longe de ser um excesso de política, é uma experiência de negação da política e de negação da liberdade (cf. TASSIN, 1997, p. 384). O totalitarismo não seria então uma prova de quanto a política seria oposta à liberdade, mas um exemplo muito evidente de como a negação da política culmina na negação da liberdade. Arendt depois defende que a liberdade é o sentido da política (cf. ARENDT, 2013, p. 161), e que proteger a liberdade é um dos objetivos mais elevados da política (cf. GAFFNEY, 2015, p. 07). 0 enfrentamento do totalitarismo deveria ser feito não pelo abandono da política, mas justamente pelo seu resgate. Por isso era tão importante para Arendt desfazer o equívoco citado. Era exatamente no modo como o totalitarismo se relacionava com a liberdade humana que residia, segundo Arendt, a diferença que faz do totalitarismo algo novo em relação a outros regimes autoritários.

Não é apenas o ataque à liberdade, mas o modo como este ataque se dá que é um dos elementos diferenciadores dos regimes totalitários em relação às antigas tiranias e as modernas ditaduras (cf. TASSIN, 1997, p. 372), revelando-o como um fenômeno totalmente novo. 0 processo que o totalitarismo deseja colocar em funcionamento tem como objetivo mudar a própria natureza do homem, de modo que ela não gere quaisquer obstáculos ao desenrolar da lei da natureza ou da história. A condição humana demanda a sobreposição de um mundo artificial 
construído pelo homem sobre a natureza ${ }^{4}$ (cf. CANOVAN, 1995, p. 25). Neste sentido, a paradoxal "natureza" do homem, caracterizada pela imprevisibilidade, o coloca em condições conflitantes com a própria natureza física, que é marcada pela previsibilidade. A natureza possui seu ciclo constante e repetitivo, e o homem se mostra um ponto fora desta lógica por meio da sua espontaneidade e sua capacidade para iniciar algo novo. Por isto, o projeto totalitário não se resume a matar fisicamente o homem (e o fez com aqueles que foram eleitos inimigos objetivos), mas mudar a própria natureza "antinatural" do ser humano, tornando-o cada vez mais um espécime natural, como qualquer animal, privado de liberdade e individualidade 5.

Comentamos acima que a interpretação totalitária da lei inverte o sentido da lei considerado enquanto nomos, inversão que é fundamental para abertura do caminho para o domínio total. Para Arendt tanto o direito grego quanto o direito romano apresentavam a lei como um componente artificial e feito pelos homens (cf. GOLDONI \& MCCORKINDALE, 2012, p. 20). Apesar das diferenças entre estas duas concepções de lei trabalhadas por Arendt, a lex romana e o nomos grego, há uma outra semelhança entre ambas que queremos destacar: nas duas concepções a lei se relaciona com a livre ação política ${ }^{6}$ dos homens ${ }^{7}$. É exatamente esta liberdade que o totalitarismo vai querer eliminar, invertendo o sentido da lei, fazendo com que a liberdade seja

\footnotetext{
${ }^{4}$ Ver também: "Unlike other animals, however, which live a natural life on the earth as it is given to them, human beings have constructed a world of their own over and above the natural Earth" (CANOVAN, 1995, p. 106).

5 "A desvairada fabricação em massa de cadáveres é precedida pela preparação, histórica e politicamente inteligível de cadáveres vivos". (ARENDT, 2014, p. 593)

6 "As leis positivas, portanto, destinam-se primariamente a funcionar com elementos estabilizadores para os movimentos dos homens, que são eternamente mutáveis" (ARENDT, 2014, p. 615). Também: "As leis circunscrevem cada novo começo e, ao mesmo tempo, asseguram a sua liberdade de movimento, a potencialidade de algo inteiramente novo e imprevisível..." (ARENDT, 2014, p. 619).

${ }^{7}$ A diferença é que na lex romana a formulação da lei já é exercício de política, e no nomos grego, a lei é uma realidade pré-política, fundamental para o exercício da política, mas não ainda política. "Enquanto o nomos gregos expressa a ideia de demarcação, a lex romana representa relacionamento" (VOLK, 2010, p. 776). Para os romanos a lei era concebida como ponte, como criadora de laços duradouros, era relacional uma vez que nascia do livre debate e consenso entre os homens. Já para os gregos a lei não era fruto de uma relação política entre iguais, ela era uma barreira fixa que definia os limites, circunscrevia e protegia um espaço onde os homens podiam criar relações e vivenciar a ação política livremente (cf. ARENDT, 2013, p. 241-244), era uma barreira permanente que com sua força estabilizadora ajudavam a estabelecer internamente uma relação entre os cidadãos da polis (cf. VOLK, 2010, p. 777). A relação de liberdade entre iguais era posterior à lei, o legislador nem precisava ser da polis, era como um arquiteto, um construtor da lei (cf. SORIANO, 2015, p. 161), o que acontecia dentro do espaço circunscrito pela lei é que poderia ser chamado propriamente de política. Neste contexto, a concepção de lei como nomos era importante como proteção à possibilidade de movimento dos homens (o totalitarismo eliminou os movimentos dos homens para dar espaço ao movimento contínuo da natureza e da história).
} 
reservada ao movimento contínuo da natureza e da história, e não mais aos homens. 0 primeiro instrumento utilizado pelo totalitarismo para quebrar as barreiras protetoras da lei é o terror, que depois se tornará a própria legalidade do totalitarismo (cf. ARENDT, 2014, p. 618). Destruídas todas as barreiras que sustentam um espaço onde as pessoas podiam aparecer livremente e expressarem a própria singularidade, o terror tem aberto o caminho para efetivar o projeto totalitário de homogeneização dos homens. Neste processo o terror será acompanhado de outro instrumento fundamental ao totalitarismo, a ideologia.

Para entendermos qual o papel e o modo de implementação do terror e da ideologia nos regimes totalitários é fundamental recordar a fala de Arendt a respeito da essência e dos princípios dos governos em Montesquieu. Para Arendt Montesquieu foi o último a investigar a natureza dos governos (o que faz com que um governo seja o que é), mas foi o primeiro a acrescentar a necessidade de se investigar o princípio dos governos (o que faz um governo agir como age) (cf. ARENDT, 2011, p. 348). Segundo Arendt, para Montesquieu a estrutura dos governos por si só é incapaz de motivar qualquer ação (cf. ARENDT, 2013, p. 99). Para Montesquieu a legalidade apenas pode por limitações às ações, mas não pode inspirá-las, sendo necessário alguma coisa que dê conta das ações concretas das pessoas que vivem dentro dos limites legais, que é justamente o papel dos princípios dos governos (cf. ARENDT, 2013, p. 110).

Montesquieu descreve três princípios de acordo com os tipos de governos.

... a virtude, que inspira as ações numa república; a honra, que inspira os súditos de uma monarquia; e o medo, que guia as ações numa tirania, a saber: o medo que os súditos têm do tirano e dos outros súditos e o medo que o tirano tem dos súditos. (ARENDT, 2013, p. 112).

Enquanto a virtude nasce do amor à igualdade, a honra nasce do amor à diferença... (cf. ARENDT, 2013, p. 113). Montesquieu não aponta a experiência fundamental da qual surge o medo, segundo Arendt, porque ele, assim como toda a tradição, “...não pensava na tirania como um autêntico corpo-político" (ARENDT, 2013, p. 116). 0 medo, como princípio tem ligação com a experiência de falta de poder daquelas situações em que somos incapazes de agir. 0 medo é, do ponto de vista da política, “...o desespero com a própria impotência quando atingimos os limites dentro dos quais a ação é possível" (ARENDT, 2013, p. 116). Neste sentido, o medo não 
seria propriamente um princípio de ação, mas um princípio anti-político, por meio do qual surge a vontade do tirano para dominar e subjugar a todos e a preparação do súdito para a recepção da dominação (cf. ARENDT, 2013, p. 116-117). 0 resultado é uma desconfiança cada vez maior, que torna impossível o agir concertadamente, e aos súditos resta a experiência de estar totalmente só, “... que é estar impotente (...), incapaz de angariar a ajuda dos meus semelhantes" (ARENDT, 2013, p. 117).

A compreensão dos governos a partir da necessidade de se apontar sua natureza e seu princípio (cf. ARENDT, 2011, p. 358), será usada por Arendt na explicitação da sua visão do totalitarismo. Para Arendt, enquanto a lei é a essência da república, o terror é a essência do totalitarismo (cf. ARENDT, 2011, p. 361). Seguindo este paralelo, à lei cabe criar as barreiras (ou fronteiras) fixas que protegem e resguardam a liberdade de movimento e ação dos homens, enquanto ao terror cabe a destruição destas mesmas barreiras afim de fixar os homens, anulando a liberdade e então abrir passagem ao movimento da lei da natureza ou da história (cf. ARENDT, 2011, p. 361). 0 terror cumpre seu papel através de um processo de homogeneização dos homens, por meio do que Arendt chamou de cinturão de ferro, que anula os canais de comunicação entre os indivíduos e os...

...prende todos juntos com tanta força que parece fundi-los entre si, como se fossem um único homem. (...) 0 terror forja essa unidade de todos os homens ao abolir as fronteiras da lei que provê o espaço de liberdade para cada indivíduo". (ARENDT, 2011, p. 361-362).

O objetivo por trás deste esforço é sempre lidar com a insistente imprevisibilidade que ronda os homens se forem considerados em sua pluralidade. Uma vez organizada a humanidade enquanto o homem e não como os homens, organizada como uma unidade que marcha segundo o movimento da natureza e da história, o terror então conseguia acelerar a força deste movimento (cf. ARENDT, 2011, p. 361).

Vimos como a sociedade massificada da modernidade torna cotidiano o “...estado paradoxal de solidão em que as pessoas vivem lado a lado com as outras, mas não compartilham o 
mundo comum"8 (KING, 2015, p. 65). 0 terror totalitário irá aprofundar este estado de solidão e a incapacidade de compartilhamento do mundo comum. 0 terror totalitário “...destrói qualquer espaço entre os homens, massificando-os, constitui-los como espécie, cria o Uno a partir do múltiplo" (AMIEL, 1996, p. 41).

O terror é a força que abre espaço para o movimento cada vez mais livre da natureza e da história, mas não é o único instrumento utilizado pelo totalitarismo. Além de anular o espaço público, fomentando o isolamento e gerando a homogeneização dos indivíduos, o totalitarismo busca também mudar nas pessoas o próprio modo de "ver" o mundo. Com esta mudança as próprias pessoas são preparadas para se ajustarem às leis eternas da natureza e da história”9 . 0 totalitarismo faz isso por meio da ideologia (cf. ARENDT, 2011, p. 363). A ideologia seria a expressão intelectual da realidade "atestada" pela lei do movimento da natureza e da história (cf. JARDIM, 2011, p. 39). A bem da verdade, o totalitarismo não teria propriamente um princípio de ação, em vez disso o totalitarismo se baseia num novo princípio que descarta a ação ${ }^{10}$ (e toda a imprevisibilidade que os pressupostos da ação produzem) (cf. ARENDT, 2011, p. 368). Neste sentido, podemos dizer que o princípio descrito por Montesquieu é substituído no totalitarismo pela ideologia (cf. ARENDT, 2011, p. 374-375).

Para enfrentar os fatos da realidade, de início a ideologia negará a necessidade de contato com o mundo real. Por meio da propaganda ${ }^{11}$ a ideologia busca dobrar a realidade de modo a ser coerente com a lógica desenvolvida pela própria ideologia ${ }^{12}$ (cf. CANOVAN, 1995, p. 25). Partindo de uma premissa axiomática (como a ideia de uma raça pura), a ideologia irá

\footnotetext{
8 "...the paradoxical state of loneliness in which people live cheek by jowl with others, yet do not share that common world".

9 "As ideologias são a explicação da lógica e do significado do processo histórico e sua função é organizar, por meio da doutrinação, a conduta da população para que cada um de seus membros ocupe um lugar determinado na história" (JARDIM, 2011, p. 39)

10 "Assim, o totalitarismo não precisa, no sentido estrito, de um princípio de ação, pois ao contrário, trata-se de erradicar a possibilidade em si" (AMIEL, 1997, p. 41).

11 "...os movimentos totalitários se servem da propaganda para forjar uma ideia coerente da realidade que, mesmo estando em flagrante contradição com muitos dados de realidade, é percebida como fornecendo uma visão muito mais consistente e científica do mundo" (BIGNOTO in: AGUIAR, 2001, p. 39).

120 totalitarismo irá utilizar da ideologia para transformar suas arbitrariedades em "fatos" coerentes e plenamente justificados, é exatamente "...a ideologia e sua disseminação que vão possibilitar a existência dos campos de mortes como algo normal e desejável” (AGUIAR, 2008, p. 84).
} 
desdobrar conclusões logicamente dedutíveis que em tese explicam toda a realidade e todo o desenvolvimento histórico ${ }^{13}$ (cf. VILLA, 1999, p. 91). É exatamente esse o momento em que uma ideia se torna uma ideologia, quando ela não apenas fala algo sobre o mundo, mas pretende ser o eixo de explicação de toda a historia e de toda a realidade ${ }^{14}$. Se para a ideologia é importante lidar com o obstáculo da imprevisibilidade, a força da lógica é o melhor caminho para montar uma cadeia de previsibilidades. "Arendt identifica a força coercitiva da lógica como a espinha dorsal das ideologias totalitárias" (VILLA, 1999, p. 91). Como dizia Arendt, "uma ideologia é bem literalmente o que o seu nome indica: é a lógica de uma ideia" (ARENDT, 2014, p. 612). Aceitando-se um axioma inicial, e seguindo as consequencias lógicas que dele decorrem, não haveria porque se sujeitar às instabilidades da realidade. A sobreposição da ideia sobre os fatos na ideologia representa o primado da lógica sobre o conteúdo. Uma vez que “...a lógica e toda a evidência com que procede o raciocínio lógico podem alegar uma confiabilidade totalmente independente do mundo e da existência de outras pessoas" (ARENDT, 2011, p. 341).

Aqui chegamos a outro procedimento executado pela ideologia para enfrentar os obstáculos da imprevisibilidade e a incoerência do mundo humano: além de negar a realidade, a ideologia considera completamente dispensável a interação com outros homens. Na realidade, a dispensa da interação será profundamente necessária aos objetivos da ideologia, uma vez que "os indivíduos, tendo perdido contato com outros indivíduos, não tinham capacidade para verificar o que era real e o que era o produto da propaganda" 15 (TOPOLSKI, 2015, p. 49). É, portanto, muito importante para a ideologia que as pessoas se encontrem cada vez mais no isolamento. Para Arendt, os homens têm acesso ao mundo pela interação, é neste contato que a

\footnotetext{
13 Ver também: "La sua caratteristica è pertanto quella di applicare agli eventi la legge dello sviluppo logico di quella idea, come se i processi storici fossero accessibili solo attraverso questo corso. Entro tale logica deduttiva, la parola "razza" nel razzismo indica l'idea mediante la quale il movimento storico appare secondo uno sviluppo coerente, disinteressandosi di una presunta esplorazione scientifica delle "razze" umane" (MATTUCCI, 2012, p. 159).

${ }^{14}$ A natureza da ideologia é profundamente oposta ao modo que Arendt compreende o modo humano de acesso à realidade. Para Arendt nós só podemos acessar efetivamente a realidade quando estamos junto a outros, e quando é considerada o conjunto de perspectivas (opiniões) sobre o mundo. Quando apenas uma visão de mundo é considerada, então já perdemos o acesso ao mundo (ROVIELLO, 1997, p. 116-117), o que é um dos objetivos da ideologia.

15 "The individuals, having lost touch with other individuals, had no ability to verify what was real and what was the product of propaganda".
} 
realidade nos é dada, testada e confirmada (cf. ROVIELLO, 1997, p. 134). É através do senso comum $^{16}$, o que Arendt chamou de um sexto sentido que interliga as diferentes percepções que eu e outros junto compartilham do mundo, que a nossa experiência e compreensão do mundo é possível. Neste sentido, quanto mais isolados, menos contato com a realidade nós temos ${ }^{17} \mathrm{e}$ mais vulneráveis à propaganda ideológica nos tornamos. É neste ponto que a ideologia irá insistir, tendo a força da lógica como condutora deste processo, a partir do qual o senso comum e o contato com a realidade são substituídos pela aceitação de uma "realidade mais verdadeira" fornecida pela ideologia.

É a logicidade que apela aos seres humanos isolados, pois o homem - no completo isolamento, sem nenhum contato com seus semelhantes e, portanto, sem nenhuma possibilidade real de experiência - não tem mais nada a que possa recorrer, a não ser as mais abstratas regras do raciocínio. (ARENDT, 2011, p. 377)

Não temos apenas um discurso enganador sobre o mundo, a ideologia totalitária ultrapassa os limites do discurso para impor ao real a própria coerência (cf. ROVIELLO, 1997, p. 129). Onde o indivíduo que foi cooptado vivencia uma recusa ativa da abertura ao mundo, erguendo uma parede entre si próprio e o não-sentido do mundo (cf. ROVIELLO, 1997, p. 129). Terror e ideologia, na execução do poder total, buscam a eliminação de tudo aquilo que pode oferecer-lhes resistência: a legalidade, a pluralidade e a realidade (cf. ROVIELLO, 1997, p. 130).

Terror e ideologia operaram no intuito de criar um ambiente marcado pelo desprezo da realidade e pelo primado da lógica, de modo a facilitar e acelerar o movimento da lei da natureza ou da história. Ambos atacam as bases da interação humana. Com o cinturão de ferro, que ao desfazer o espaço entre os homens (espaço que os uni e os distingue) isola-os e o os homogeneíza. Sob a forma de um super indivíduo, esse "um homem só" (isolado e uniformizado) recebe a lógica de uma ideia que lhes daria acesso a uma realidade mais verdadeira. Sem

\footnotetext{
$16 \mathrm{Um}$ dos conceitos que mais evidencia a importância da interação humana para o nosso acesso à realidade é o senso comum. 0 senso comum será atacado no totalitarismo, que o anulará e colocará em seu lugar a ideologia como uma pretensa base de acesso à realidade (uma realidade mais "coerente" e mais previsível).

${ }^{17}$ Além da importância de se construir um contexto de fuga ou dispensabilidade da realidade, o isolamento é fundamental para o totalitarismo também porque “...qualquer grupo de gente reunida por algum interesse comum constitui a ameaça suprema à dominação total. Apenas os indivíduos isolados podem ser dominados por completo" (ARENDT, 2011, p. 375).
} 
acesso à realidade, porque isolado da vida compartilhada com outros, e sem acesso à sua própria singularidade, o homem perde acesso ao comum e ao singular, e só lhe resta a vida em que ele é absolutamente apenas um, o homem solitário. Este processo, como vemos, vai além do isolamento. Isolados os homens permanecem com a vida interior preservada, e a espontaneidade ainda não estaria anulada. Para conseguir seu objetivo de domínio total, o totalitarismo terá de mergulhar esses homens na mais radical experiência da solidão, onde nem mesmo o mais íntimo traço de singularidade ficaria fora do seu alcance. Neste momento restariam apenas cadáveres vivos, homens supérfluos, que depois podem ser descartados. Esta radicalidade da solidão encontra lugar no instrumento que Arendt considerou a instituição central do totalitarismo (cf. ARENDT, 2014, p. 586): os campos de concentração ${ }^{18}$.

\section{Os campos de concentração e a radicalização da solidão}

Os campos de concentração são a instituição que caracteriza mais especificamente o governo totalitario (cf. ARENDT, 2014, p. 586). Segundo Aguiar, não há totalitarismo sem campos de concentração, e só por meio deles o totalitarismo pode conseguir realizar seus objetivos (cf. AGUIAR, 2008, p. 83). Nos campos o enfrentamento da imprevisibilidade humana, e a busca pela eliminação da espontaneidade humana encontram o seu ápice. Neles, o domínio e o controle são totais (cf. AGUIAR, 2007, p. 10). Em condições normais seria muito difícil implementar o objetivo totalitário da radical perca da espontaneidade e a redução do homem a um mero feixe de sensações, "...é somente nos campos de concentração que essa experiência é possível” (ARENDT, 2014, p. 582). 0 domínio total impetrado nos campos leva ao extremo a experiência da solidão, de modo que progressivamente os internos perdem-se da relação com o mundo e a realidade, com os outros e consigo mesmo. Este processo se completa a partir de três passos.

“O primeiro passo essencial do caminho do domínio total é matar a pessoa jurídica do homem" (ARENDT, 2014, p. 594), a começar pela desnacionalização em massa, que já se podia observar em grande parte da Europa no período do pós-guerra. Essas pessoas, aos milhares,

18 "The concentration camp represents, for Arendt, structural loneliness in its most extreme and purest form" (LUCAS, 2019, p. 5). 
estavam agora "fora da lei", e começavam a ser destituídas de sua existência, inicialmente a jurídica (cf. LAFER, 2015, p. 151). Os campos alimentaram e aprofundaram este processo de liquidação da personalidade jurídica. Surgidos fora do contexto do direito penal normal, os campos não eram propriamente uma prisão. Isso se entendemos que numa prisão há condenados por crimes previstos em lei, e que lá cumprem um castigo reparador, têm a oportunidade de uma eventual ressocialização, e a própria prisão é entendida como um instrumento de prevenção de delitos. Os campos não ressocializam ninguém, e não representam um castigo reparador de um crime, porque os internos na maioria nem mesmo crimes cometeram. Em tal contexto, os internos dos campos estavam sujeitos a todo tipo de arbitrariedades (cf. LAFER, 2015, p. 152).

“O próximo passo decisivo do preparo dos cadáveres vivos é matar a pessoa moral do homem" (ARENDT, 2014, p. 599). Os campos buscavam apagar qualquer traço da existência do interno. Para efetivar este processo, os internos eram isolados do resto do mundo, uma vez tornado prisioneiro, ninguém mais do mundo exterior iria ter notícias dele, era como se ele tivesse desaparecido, nem sequer seria declarada a morte dos prisioneiros (cf. ARENDT, 2011, p. 268). Nos campos de concentração, os prisioneiros tinham a vida ou a morte em completo anonimato, até a própria morte era roubada do indivíduo, nem mesmo a morte lhe pertencia, e se tornara apenas o desfecho de uma vida que já não se sabia que existia (cf. ARENDT, 2014, p. 600). Segundo Aharony, dos três passos o segundo é o menos evidente, não dependia de lei anteriores, mas de práticas sistemáticas cotidianas que passo a passo minavam a capacidade de ação e consciência moral adequadas (cf. 2010, p. 200). Os internos lutavam continuamente pela vida, e muitas vezes se encontravam em situação que frustravam qualquer sentimento de solidariedade entre os presos, muitas vezes colocados uns contra os outros pelos soldados. Os homens da SS implicavam frequentemente os internos em seus crimes, obrigando-os a participarem de ações que resultavam na morte de outros internos. Cria-se condições em que a consciência deixa de ser adequada e fazer o bem se torna inteiramente impossível (ARENDT, 2014, p. 600). Neste contexto todas as escolhas acabam sendo estritamente $\operatorname{trágicas}^{19} .0$ que fazer

\footnotetext{
19 "Arendt is not denying that some choices could still be made, that the imperative of survival could issue in greater and lesser betrayals of one's fellows. The point is that when the choice is between murder, theft, or
} 
quando em suas mãos está a possibilidade de trair e levar a morte os próprios amigos, ou no lugar decidir enviar o cônjuge e os filhos aos campos? (cf. VILLA, 1999, p. 27). A destruição do sujeito moral nos campos acarretava as seguintes consequências: "(1) Não há espaço para protestos de consciência; (2) A luta constante pela vida elimina a solidariedade humana e leva ao completo isolamento; (3) As vítimas se tornam cúmplices nos crimes totalitários" (AHARONY, 2010, p. 200).

Morta a pessoa moral, o que falta para se alcançar o objetivo de transformar os homens em mortos-vivos é anular a individualidade, a identidade única do indivíduo (cf. ARENDT, 2014, p. 601). Este terceiro passo finaliza o processo de dominação total e representa a tarefa mais difícil que o totalitarismo se propõe (cf. AHARONY, 2010, p. 202). “A dominação total só é alcançada quando o ser humano (...) foi transformado num ser completamente condicionado, cujas reações podem ser calculadas" (ARENDT, 2011, p. 268). Trata-se do desenraizamento completo do ser humano, que perde as relações, a capacidade de agir e de perceber a realidade. Esse processo já tem início no modo em que os internos eram transportados para os campos, amontoados em trens de carga, e lá chegando o tratamento era absolutamente uniformizado, sem qualquer referência à singularidade (cf. JARDIM, 2011, p. 41). Nos campos, os internos eram submetidos a altíssimo grau de exaustão física e de humilhação, um processo contínuo e calculado que visava anular a dignidade humana (cf. AHARONY, 2010, p. 203). Era a reta final do processo de destruição de qualquer resquício da personalidade e espontaneidade humana (cf. VILLA, 1999, p. 27). Neste momento a morte da individualidade arrasta consigo a morte da pluralidade, uma vez que a alienação de si mesmo e a alienação do mundo andam de mãos dadas (cf. ROVIELLO \& TEMERSON, 2007, p. 924), já não há um individuo capaz de reportar-se a um mundo comum, capaz de tornar-se "dois-em-um", há apenas uma singularidade absolutamente só, “...nada resta senão horríveis marionetes com rostos de homem, todas com o mesmo comportamento do cão de Pavlov, todas reagindo com perfeita previsibilidade mesmo quando marcham para a morte" (ARENDT, 2014, p. 603).

betrayal, on the one hand, and a suicidal adherence to ordinary morality, on the other, the decisions of conscience become "absolutely questionable and equivocal." (VILLA, 1999, p. 27). 
Ao final destes três passos não há mais a capacidade do indivíduo de se ver como doisem-um, que é preservada se homem apenas se encontra só. Também não há mais a capacidade de pensamento ou fabricação que ainda se resguarda quando estamos isolados. Arendt nos recorda que “...na solidão sou realmente apenas um” (2014, p. 636). Na solidão totalitária estão anuladas a capacidade de compartilhar um mundo com outros (seja porque pelo terror os espaços públicos foram destruídos ou porque pela ideologia as pessoas são levadas ao abandono do mundo e da realidade) e também está anulada a raiz da capacidade interior de começar coisas novas (cf. LUCAS, 2019, p. 3). É a concretização limite da negação do comum e do singular na vida humana.

Já não temos de modo algum o contato com os outros, e perdemos o próprio eu, o que é o mais insuportável da solidão (cf. ARENDT, 2014, p. 636). A perca dos contatos e da abertura ao mundo operada no contexto dos campos faz esvair a própria individualidade, e neste momento, sozinhos (sem os outros e sem nós mesmos), o homem perde qualquer sinal de diferenciação. A espontaneidade humana, tão atacada pelo totalitarismo, dá lugar finalmente à previsibilidade e à uniformização. Sem a possibilidade de singularização o que resta é uma massa de indivíduos sem laços. E "em um mundo que não é mais comum, os homens hão de igualar-se entre si, até não poderem mais distinguir-se" (ARENDT, 2006, p. 486). Alcança-se enfim um “Homem" previsível e controlável, o cão de Pavlov, "o modelo de 'cidadão' de um estado totalitário" (AHARONY, 2010, p. 202).

\section{Conclusão}

Um dos grandes méritos de Hannah Arendt foi conseguir identificar em situações aparentemente banais ou cotidianas, algo que representa um perigo real.É assim quando ela reflete sobre o mal banal, nos alertando que o mal não precisa vir apenas de onde é evidente, que ele pode ser banalizado a tal ponto que mesmo o mais típico pai de família, trabalhador dedicado, pode ser capaz de praticá-lo, com consequências inimagináveis, tendo-se em vista o autor destes males. Foi exatamente esta a reflexão que Arendt nos fez em Eichmann em Jerusalém, deixando-nos um alerta importante sobre as possibilidades do mal, e como ele pode se originar 
onde nunca esperamos. Neste artigo pude evidenciar outro momento em que Arendt novamente identifica um perigo real advindo de uma situação cotidiana, o perigo que se esconde no contexto da solidão. Não que este conceito já não tivesse uma conotação negativa, ou muitas vezes fosse vista com certo pesar, como quando se pensa na situação de solidão a que muitas vezes são conduzidos os idosos, especialmente numa sociedade onde o fazer é sempre o mais importante. 0 idoso que não consegue mais produzir como antes (no mundo do trabalho), ou não consegue mais comunicar-se com a mesma desenvoltura da juventude, acaba sendo deixado à parte de sociedade, silenciado, e jogado na solidão. No entanto Arendt explora este conceito com uma conotação política pouco ou nenhuma vez explorada, alertando sobre como a solidão pode ser fabricada intencionalmente como ferramenta de dominação, ou preparação para a instauração de regimes autoritários. Neste sentido, considero a reflexão arendtiana sobre a solidão uma das mais importantes contribuições da autora para compreendermos o nosso tempo, e os perigos que o rondam. Por mais que na obra da autora esta reflexão conduza ao alerta específico do totalitarismo, entendo que sua reflexão nos oferece ferramentas para lidar com vários perigos além do totalitarismo. Em seu tempo ela lidou especificamente com o totalitarismo, que à época era onde residia a máxima experiência da solidão, mas nada impede que outras manifestações autoritárias reeditem o uso da solidão em seu cerne, de modo tão ou mais profundo que o totalitarismo. No entanto, de posse das reflexões de Arendt, podemos identificar mais facilmente quando, nos mais diversos contextos, as sementes da solidão estão sendo plantadas. São elementos que nos permitem perceber com mais clareza as ervas daninhas que surgem num jardim, e que nos ajudam a prevenir para que o jardim não se torne um deserto.

\section{Bibliografia}

AHARONY, M. Hannah Arendt and the Idea of Total Domination. Holocaust and Genocide Studies, 24, no. 2 (Fall 2010): 193-224.

AGUIAR, O. Filosofia e Política no Pensamento de Hannah Arendt. Fortaleza: EdUFC, 2001.

AGUIAR, 0. A tipificação do Totalitarismo. Revista dois pontos, v. 5, n. 2, 2008, p.73-88.

AGUIAR, O. A experiência totalitária em Hannah Arendt. Revista de Ciências Sociais, v. 30, n.1/2, 1999.

AGUIAR, O. Veracidade e propaganda em Hannah Arendt. Cadernos de Ética e Filosofia Política, v. 10, n. 1, 2007. 
AMIEL, A. Hannah Arendt: Política e Acontecimento. Lisboa: Instituto Piaget, 1997.

ARENDT, H. Compreender: Formação, exílio e totalitarismo. São Paulo: Companhia das Letras; Belo Horizonte: Editora UFMG, 2011.

ARENDT, H. Diário Filosófico: 1950 - 1973. Barcelona: Herder, 2006.

ARENDT, H. Homens em Tempos Sombrios. São Paulo: Companhia das Letras, 2008.

ARENDT, H. As Origens do Totalitarismo. Trad. R. Raposo. São Paulo: Companhia das Letras, 2014.

ARENDT, H. A promessa da política. 5a ed. Rio de Janeiro: Difel, 2013.

CANOVAN, M. Hannah Arendt: a re-interpretation of her political thought. Cambridge: Cambridge University Press, 1995.

DUARTE, André. Singularização e subjetivação: Arendt, Foucault e os novos agentes políticos do presente. Revista Princípios, v. 19, n. 32, 2012.

ESQUIROL, J. M. Hannah Arendt y el totalitarismo: Implicaciones para una teoría política. CONVIVIUM: Revista de Filosofia, n. 2, 1991.

GAFFNEY, J. Another Origin of Totalitarianism: Arendt on the Loneliness of Liberal Citizens. Journal of the British Society for Phenomenology, 2015.

GOLDONI, M.; MCCORKINDALE, C. (Eds.) Hannah Arendt and the Law. Hart Publishing, 2012.

JARDIM, E. Hannah Arendt: pensadora da crise e de um novo início. Rio de Janeiro: Civilização Brasileira, 2011.

KING, R. H. Arendt and America. Chicago: The University of Chicago Press Chicago and London, 2015.

LAFER, C. A Reconstrução dos direitos humanos: um diálogo com o pensamento de Hannah Arendt. São Paulo: Companhia das Letras, 2015.

LUCAS, S. D. Loneliness and appearance: Toward a concept of ontological agency. European Jounal of Philosophy, 2019.

ROVIELLO, A.-M. Senso Comum e Modernidade em Hannah Arendt. Lisboa: Instituto Piaget, 1997.

ROVIELLO, A.-M.; TEMERSON, C. The Hidden Violence of Totalitarianism: The Loss of the Groundwork of the World. Social Research, v. 74, n. 3, Hannah Arendt's Centenary: Political and Philosophical Perspectives, Part I, 2007.

SORIANO, A. B. La génesis del pensamiento jurídico de Hannah Arendt. Tesis doctoral, Programa de Doctorado en Derecho, Universidade da Coruña - UDC, 2015. $375 f$.

TASSIN, E. Hannah Arendt et la spécificité du totalitarisme. Source: Revue Française d'Histoire des Idées Politiques, No. 6, Dictature absolutisme ettotalitarisme: Colloque des 15 et 16 mai 1997.

TOPOLSKI, A. Arendt, Levinas and a Politics of Relationality. New York: Rowman \& Littlefield International, 2015.

VILLA, D. R. Politics, philosophy, terror: essays on the thought of Hannah Arendt. Princeton: Princeton University Press, 1999.

VOLK, C. From nomos to lex: Hannah Arendt on law politics, and order. Leiden Journal of International Law. Volume 23, Issue 04. December 2010. 
A solidão como experiência central no totalitarismo no pensamento de Hannah Arendt DOI: $10.20873 / \mathrm{rpv} 6 \mathrm{n} 2-05$

\section{Antonio Glauton Varela Rocha}

Doutor em Filosofia pela Universidade Federal do Ceará - UFC. Professor do Curso de Filosofia do Centro Universitário Católica de Quixadá - UNICATOLICA. 